\title{
Gramática discursivo-funcional e teoria da gramaticalização: revisitando os usos de [diski] no português brasileiro
}

\author{
Functional discourse grammar and theory of \\ grammaticalization: reviewing the uses of [disk ${ }^{i}$ in \\ Brazilian Portuguese
}

Vânia Casseb-Galvão ${ }^{1}$

RESUMO: Este texto traz um estudo dos usos da construção [diski] no português do Brasil, com base em uma proposta descritiva que equaciona postulados da Gramática Discursivo Funcional e da Teoria da Gramaticalização. O objetivo é promover uma análise ampla desses usos e obter contrapontos descritivos satisfatórios em relação ao paradigma evidencial constituído pelos diferentes padrões de funcionalidade de [diski].

Palavras-chave: evidencialidade, [diski], gramática discursivo-funcional, gramaticalização.

\begin{abstract}
This paper studies the uses of [diski] in the Brazilian Portuguese language, with a descriptive proposal that combines Functional Discursive Grammar and Grammaticalization Theory-based approaches. The aim of the paper is to widely analyze these uses and to show satisfactory descriptive counterpoints in relation to the evidential paradigm consisting of different patterns of functionality of [disk'].
\end{abstract}

Keywords: evidentiality, [diski], functional discourse grammar, grammaticalization.

1 Universidade Federal de Goiás. E-mail: vcasseb2@terra.com.br 


\section{Introdução}

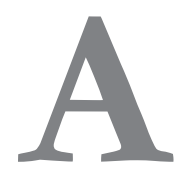

Apresento os resultados da pesquisa que investiga, na perspectiva da Gramática Discursivo-funcional (GDF) e da Teoria da Gramaticalização (TG), os usos de [diski] no português do Brasil, construção derivada de dizer que, conforme Casseb-Galvão (2001), expressa diferentes noções evidenciais (boato, verdade geral, mito etc). Pretende-se promover uma análise ampla e obter contrapontos descritivos satisfatórios entre os usos integrantes do paradigma evidencial constituído pelos diferentes padrões de funcionalidade de [diski]. O modelo de gramática esboçado na GDF por Hengeveld; Mackenzie (2008), Mackenzie; Gomes-González (2004, 2005), entre outros, é, presumivelmente, adequado para explicar as diferentes possibilidades semântico-discursivas e estruturais desses usos. Isso porque a GDF faz uma distinção minuciosa entre os níveis de representação subjacente das expressões lingüísticas: interpessoal, representacional, morfossintático e fonológico. Esta distinção contempla uma organização hierárquica rígida entre esses níveis, e, por ser uma teoria ampla de interação verbal, a GDF prioriza uma análise que contempla a integração entre os componentes contextual, conceptual e gramatical da linguagem. Em outras palavras, a GDF permite uma descrição além dos limites oracionais, operando com dimensões discursivas maiores e priorizando o componente discursivo-pragmático.

A análise pretende dar conta do estatuto categorial, das diferentes possibilidades semântico-discursivas e estruturais dos usos não predicativos de "diz que", [diski], do rearranjo sistêmico que eles promovem e dos deslizamentos sistêmico-funcionais que constituem. Dentre os diferentes usos de [diski] observados no português do Brasil, ocorrências de 1 a 4, em (1), o [diski introduz um enunciado, em (2), introduz uma unidade discursiva maior, uma narrativa de mito:

2 Registro escrito do uso não-predicativo. Apenas autores, procurando reproduzir a "cor local", como os regionalistas, tentam uma aproximação com a forma fonética inovadora, mas não há uma grafia única para esses usos (diz-que, diz que) no português brasileiro. 
(1) $\left[\text { disk }^{i}\right]_{1}$.

Que tem?! E o patrocínio resultante que a Guida dispensa ao cabra? Não, por trás de tudo aquilo só cego não vê a sombra dela... - Mas não diz que basta o adultério para produ₹̨ir o divórcio perpétuo? obtemperou o Miguel. (DGP) ${ }^{3}$

(2) $\left[\text { diski }_{2}\right]_{2}$.

Diz que lá na lonjura do tempo, no comecinho de todas as coisas, existiam três irmãos. Dois eram bomens, e a irmã, Onbianmuaçabê, era moça bonita, chamada Uniaí. (LG) ${ }^{4}$

(3) $\left[\right.$ diski $_{3}$.

O nosso brinquedo se acabou cedo ca notícia do baruio que houve da outra banda... Diz que puxaram faca, e foi pau por riba do tempo. Sabe quem passou por aqui se escondendo e me contou? Foi o Naiú, ali da Seá Dona Guidinha. (DGP)

(4) $\left[\text { disk }^{i}\right]_{4}$.

Estas férias diz-que não é pra en fazer nada. Qual! descobri um livro de vulgarização do Wella, The Science of Life, que é uma coisa magnífica. (MA $)^{5}$

Pretendeu-se, portanto, responder às seguintes perguntas:

1. Como esses usos podem ser descritos segundo a GDF?

2. Segundo a GDF, todos esses usos são evidenciais?

3. Em caso negativo, que categorias eles integram?

4. Em que nível de constituição linguística cada um desses usos é relevante?

5. Segundo os parâmetros da GDF, que contínuo de mudança, ou, mais especificamente, de gramaticalização, esses usos configuram?

6. Em que medida este trabalho contribui para a GDF?

Para promover a análise, atentarei para postulados teóricos da GDF relevantes para os propósitos da pesquisa, tendo como referência principal Hengeveld; Mackenzie (2008). Também apresentarei aspectos da gramaticalização de dir. que, conforme Casseb-Galvão (2001), especialmente, quanto à determinação da forma fonte, e enfocarei o tratamento da gramaticalização na GDF. Em seguida, tratarei da evidencialidade na perspectiva da GDF a partir de Hengeveld; Mackenzie (2008) e Hattnher; Hengeveld (não publicado).

\footnotetext{
3 Romance regionalista "Dona Guidinha do Poço".

4 Lenda do Guaraná.

5 Carta de Mário de Andrade - poeta modernista brasileiro.
} 
Descreverei os usos de [diski], a partir de dados arrolados por Casseb-Galvão (2001), Costa (2006), Corsi (2008) e Leal (2009). Os dados serão descritos com base no pressuposto de que o paradigma formado pelos usos predicativos e não predicativos de dir que constitui um contínuo de gramaticalização que tem como forma fonte a predicação matriz (ele) dir.que (Casseb-Galvão, 2001), como um de seus pontos intermediários o uso "diz-se que", e, como pontos mais extremos os usos não predicativos de [diski], que atuam em camadas mais altas da organização lingüística postulada no modelo da GDF.

As conclusões serão esboçadas considerando-se a adequação do modelo da GFD às especificidades do fenômeno e às pretensões analíticas.

\section{Postulados teóricos relevantes da GFD}

\subsection{Considerações gerais}

A GDF se distingue de outras teorias linguísticas de orientação estrutural e funcional por vários fatores, entre os quais, o reconhecimento da organização linguística em progressão top-down, ou seja, do discurso para as unidades menores; a noção de ato discursivo como unidade básica de análise; a inclusão de representações morfossintáticas e fonológicas como parte da estrutura subjacente dos Atos Discursivos, ao lado das representações de suas propriedades pragmáticas e semânticas; e a vinculação dos Componentes não-gramaticais _ Conceptual, Contextual e Output (de Saída) _ com o Componente gramatical.

Segundo Hengeveld; Mackenzie (2008: 6-7), ao Componente Conceptual cabe o desenvolvimento da intenção comunicativa relevante para a atualização da fala e as conceptualizações associadas aos eventos extralinguísticos relevantes, é a força que dirige o Componente Gramatical. O Componente Contextual é o domínio da descrição do conteúdo e da forma discursiva relativas ao discurso precedente e atualizado, é o definidor do conjunto discursivo em que o evento de fala acontece e das relações sociais entre os participantes. O Componente de Saída gera os sinais acústicos ou expressões ortográficas que carregam a informação provida pelo Componente Gramatical.

6 Forma recorrente no português europeu. Informação obtida a partir de discussão no Grupo "Discurso e Literacia" (ILTEC-Lisboa), especialmente, pela intervenção de Carlos Gouveia, Mário Martins e Riccardo Giomi. 
Um modelo de organização top down está pautado na noção de que uma gramática será mais eficiente na medida em que sua organização reflita o processamento da linguagem dos indivíduos, ou seja, parte do presuposto de que o processo de produção da linguagem parte da intenção para a articulação da expressão linguística atualizada.

Em termos de Hengeveld (2004), o caráter funcional do modelo reside no fato de que ele permite distinguir a estrutura das unidades linguísticas em termos do mundo que elas descrevem e das intenções com as quais elas são produzidas, ou seja, em termos de suas funções representacional e interpessoal. Tudo isso é modelado a partir de uma implementação dinâmica da gramática das línguas, o que envolve simultaneidade, mas também anterioridade, entre as ações linguísticas e entre os domínios que elas configuram.

Esse modelo de descrição gramatical distingue duas principais operações das expressões linguísticas, a formulação e a codificação. A formulação está relacionada às regras que determinam qual constituinte valida nas línguas as representações pragmáticas e semânticas subjacentes. Nela está envolvida a seleção de frames apropriados para os níveis respectivamente relacionados a cada uma dessas representações, o Nível Interpessoal e o Nível Representacional. A formulação também envolve a inserção nesses frames de lexemas apropriados e a aplicação de operadores que simbolizam as distinções gramaticais relevantes para uma dada língua.

$\mathrm{Na}$ codificação estão envolvidas regras de conversão dessas representações pragmáticas e semânticas em representações morfológicas e fonológicas. Ela envolve a seleção de esquemas apropriados para o Nível Morfossintático e o Nível Fonológico, a inserção de morfemas gramaticais livres e presos, e a aplicação de operadores que desempenham um papel no processo de articulação do output da gramática. De acordo com Hengeveld (2004), a GDF é uma modelo de codificação das intenções.

Como consequência dessa perspectiva top-down da organização linguística é possível descrever unidades de discurso tanto maiores quanto menores que as orações, que são consideradas apenas uma das opções disponível para que o falante atue discursivamente, ou seja, podem ser descritos fenômenos de constituição gramatical interpretáveis em termos de unidades maiores que a oração simples (ou menores do que ela). 
Portanto, na GDF, a unidade básica de discurso não é a oração, mas o Ato Discursivo (A), o qual se combina com estruturas discursivas maiores como os Moves. Por outro lado, Atos Discursivos podem ser manifestados nas línguas como orações, fragmentos de orações, como sintagmas ou como palavras.

Hengeveld; Mackenzie (2008) alertam que Moves e Atos Discursivos são difíceis de definir, mas, seguindo Kroon (1995), Hannay; Kroon (2005), que, por sua vez, seguem Sinclair; Coulthar (1975), definem o Move como "a mínima unidade livre do discurso que seja capaz de entrar em uma estrutura de troca", e o Ato Discursivo como "a menor unidade identificável de comportamento comunicativo". O Move consiste em um simples Ato Discursivo central, que pode ser apoiado por um ou mais Atos Discursivos Subsidiários, os atos de atribuição (T) e de referência (R).

Esse modelo de descrição proposto pela GDF se mostra, portanto, eficiente para embasar a análise pretendida.

Uma das consequências de se entender o processameno linguístico em uma organização top down é a própria configuraçaõ do modelo, cujos níveis seguem essa mesma direção. Em outras palavras, a gramática é percorrida em seus diversos caminhos, mas sempre se tendo a realização efetiva da linguagem como o ponto de partida. Logo, postula-se que toda expressão comunicativa envolva, pelo menos, os Níveis Interpessoal e Fonológico em diferentes graus de complexidade, e são previstas camadas internas para todos os níveis de organização ${ }^{7}$.

Os níveis são organizados hierarquicamente e se realizam em uma estrutura de camadas. Há unidades específicas que distinguem as camadas em cada um desses níveis e para cada uma delas está previsto um elemento nuclear, e a incidência de operadores e de modificadores ${ }^{8}$, e a presença de funções. Um um operador corresponde a uma marcação morfossintática, prototipicamente uma flexão ou um contorno entoacional, conforme Hengeveld; Mackenzie, 2008: 65. Operadores prototípicos não podem ser modificados (op. cit.: 59) e (caso sejam palavras) são invariáveis (op. cit. p. 66) e potencialmente passíveis

Entenda-se, no entanto, que nem toda camada prevista para determinado nível é necessariamente relevante. A presença ou a ausência de uma camada pode ser determinada idiossincraticamente.

8 A natureza lexical dos modificadores faz que eles não sejam previstos para o Nível Fonológico. 
de redução fonológica (op. cit.: 112). Um modificador tem natureza lexical e corresponde prototipicamente a uma palavra ou a um sintagma. Modificadores podem ser modificados (por outros modificadores), podem ser variáveis (se a língua o permitir) e não são sujeitos à redução fonológica. Operadores provêm historicamente de modificadores. Por isso, é possível que uma forma se encontre a um estágio dado de uma língua entre as duas extremidades, o que significa que essa forma em determinados contextos funcione como modificador e em outros, como operador.

Funções também representam estratégias gramaticais, mas, diferentemente dos operadores, que incidem individualmente sobre unidades, elas tem uma natureza relacional, ou seja, relacionam unidades completas e outras unidades de uma mesma camada.

A seguir, resumo a organização dos niveis de representação gramatical e de suas respectivas camadas internas.

\subsection{Os níveis de organização distintos nas GDF}

Uma das justificativas de Hengeveld; Mackenzie (2008) para postularem a existência dos quatro níveis de organização linguística é a possibilidade de referência anafórica entre eles. Esses níveis descrevem, estritamente, as funções e os significados dos elementos linguísticos codificados na gramática de uma língua. Resumidamente, os níveis e as camadas internas que os compõem são os seguintes, começando pelos níveis da formulação, o Interpessoal e o Representacional:

\section{i. Nível Interpessoal}

O Nível Interpessoal diz respeito a todos os aspectos formais de uma unidade linguística que reflete seu papel na interação entre falante e ouvinte (Hengeveld; Mackenzie, 2008, p. 46). É o domínio das estratégias empregadas para se conseguir os objetivos comunicativos. Essas estratégias são fundadas em princípios gerais da Retórica e da Pragmática. A Retórica envolve estudos dirigidos para a maneira como os componentes de um discurso são ordenados para a realização da estratégia comunicativa e para a maneira como as propriedades formais influenciam na produção dos sentidos desejados pelo locutor. Dentro do modelo da GDF, as funções retóricas têm relação com o modo como as 
unidades linguísticas refletem a estruturação geral do discurso. A pragmática diz respeito ao molde da mensagem pelo falante a fim de atender às expectativas do estado de espírito do ouvinte.

As unidades de organização previstas para o Nível Interpessoal, em uma ordem hierárquica decrescente quanto ao escopo, são as seguintes: Move $\left(\mathrm{M}_{1}\right)>$ Ato Discursivo $\left(\mathrm{A}_{1}\right)>$ Ilocução $\left(\mathrm{F}_{1}\right)>$ Participantes $\left(\mathrm{P}_{1}\right)\left(\mathrm{P}_{2}\right)>$ Conteúdo Comunicado $\left(\mathrm{C}_{1}\right)>$ Subato de Atribuição $\left(\mathrm{T}_{1}\right)>$ Subato Referencial $\left(\mathrm{R}_{1}\right)$.

Não me deterei na definição dessas unidades individualmente, mas o farei oportunamente, caso seja relevante para a análise pretendida.

\section{ii. Nível Representacional}

Segundo Hengeveld; Mackenzie (2008), as unidades do Nível Representacional são descritas em termos das categorias semânticas que elas designam. O termo "semântico" abrange o modo como as línguas se relacionam com o mundo extralinguístico descrito e os significados de unidades lexicais e de unidades complexas isolados do modo como são usadas na comunicação.

Essa distinção é necessária porque em uma sentença como "Eu vi um leão" (Hengeveld; Mackenzie, 2008: 129), por exemplo, a expressão "um leão" pode ser considerada referencialmente tanto como um ato de referência do falante a um animal da classe dos leões como uma expressão relativa a um animal da classe dos leões. O primeiro caso traz uma perspectiva interpessoal, acional. O segundo caso traz uma perspectiva semântica, representacional. A ideia subjacente nessa distinção é a de que o falante refere, a expressão designa.

A distinção das unidades do Nível Representacioal é feita em termos das categorias ontológicas designadas, as "categorias semânticas". O critério para a distinção dessas categorias está relacionado às configurações morfossintáticas semanticamente baseadas que são permitidas nas línguas (Hengeveld; Mackenzie, 2008: 131).

Hengeveld; Mackenzie (2008), seguindo, inicialmente, Lyons (1977), mencionam que há um número básico de categorias semânticas relevantes para a análise das línguas, categorias distintas em entidades de diferentes ordens: de $1^{\mathrm{a}}$ ordem, um Indivíduo (x) (pode ser localizado no espaço e pode ser avaliado em termos de sua existência, ex. cadeira); de $2^{a}$ ordem, um Estado-de-Coisas (e) (pode ser localizado no espaço e no tempo e pode ser avaliado em termos 
de sua realidade, por exemplo, encontro); de $3^{\text {a }}$ ordem, um Conteúdo Proposicional ( $\mathrm{p}$ ) (um construto mental que não pode ser localizado no espaço nem no tempo e pode ser avaliado em termos de sua verdade, por exemplo, ideia). Hengeveld; Mackenzie (2008) acionam o quadro da Gramática Funcional (Hengeveld, 1992; Keizer, 1992; Dik, 1997a) para propor uma quarta categoria básica, a Propriedade (f), que não tem existência independente, não pode ser distinta em termos de tempo e de espaço, e somente pode ser avaliada em termos de sua aplicabilidade a um ou outro tipo de entidade ou situação que as propriedades em geral descrevem (por exemplo, cor). A Propriedade pode ser aplicada a entidades de $1^{\mathrm{a}}, 2^{\mathrm{a}}$ e $3^{\mathrm{a}}$ ordem.

Outras categorias semânticas relevantes são localização, tempo, episódio, maneira, razão e quantidade. As categorias semânticas e as unidades componentes do Nível Representacional serão definidas na medida em que isso for relevante para a descrição pretendida.

Em uma ordenação hierárquica decrescente quanto ao escopo, estão previstas para a organização do Nível Representacional as seguintes camadas: Conteúdo Proposicional (p) > Episódio (ep) > Estado-de-coisas (e) $>$ Propriedade Configuracional (f) $>$ Propriedade lexical $>$ Indivíduos (x).

As operações de Codificação são representadas no Nível Morfossintático e no Nivel Fonológico.

\section{iii. Nivel Morfossintático}

A tarefa do Nível Morfossintático é tomar o input do Nível Interpessoal e o input do Nível Representacional e fazê-los emergir em uma única representação estrutural que será convertida em uma construção fonológica no nivel seguinte, este que, afinal, será o articulador, o Componente de Saída de todo o modelo (Hengeveld; Mackenzie, 2008: 282). A estrutura input oferece a informação à qual o Nível Morfossintático aplica os seus próprios princípios de organização. O Nível Morfossintático é, portanto, apenas o codificador das informações semânticas e pragmáticas. A funcionalidade desse nível reside no fato de que ele ajuda o interlocutor a intepretar as relações de escopo (que envolve iconicidade), os limites de domìnio (que se relaciona à integridade de domínio), e as funções pragmáticas, semânticas e sintáticas (que operam uma estabilidade funcional). É o nível das operações relacionais, ou seja, ele estabelece os arran- 
jos gramaticais que exteriorizam informações semânticas e pragmáticas, sem acrescentá-las ou subtraí-las.

À organização hierárquica interna do Nível Morfossintático também é aplicada uma perspectiva top-down, mas Hengevld; Mackenzie (2008: 283) alertam que essa hierarquia está sujeita a fatores idiossincráticos. As camadas são analisadas levando-se em consideração fatores como a ordenação linear dos constituintes, o alinhamento (seleção de argumentos privilegiados), a subordinação, a inserção de expletivos (dummy) e a concordância.

Em uma ordenação hierarquica descrescente quanto ao escopo, na estruturação do Nível Morfossintático estão previstas as seguintes camadas: Expressão linguística $\left(\mathrm{Le}_{1}\right)>\operatorname{Oração}\left(\mathrm{Cl}_{1}\right)>\operatorname{Sintagma}\left(\mathrm{Xp}_{1}\right)>\operatorname{Palavra}\left(\mathrm{Xw}_{1}\right)>\operatorname{Base}\left(\mathrm{Xs}_{1}\right)$ $>\operatorname{Afixo}\left(\mathrm{Aff}_{1}\right)$.

\section{iv. Nível Fonológico}

Na Codificação, o Nível Fonológico é a parte complementar ao Nível Morfossintático. As representações fonológicas servem de input para o Componente de Saída (Hengeveld; Mackenzie, 2008: 421), e, o componente fonológico, por sua vez, recebe input dos outros três níveis (Interpessoal, Representacional e Morfossintático). O Nível Fonológico contém as representações segmentais e suprassegmentais dos enunciados.

O Nível Fonológico contém representações fonêmicas, baseadas em oposições fonológicas binárias, o que implica a consideração de segmentos fonológicos individuais (por isso a relevância da noção de pares mínimos), e de contrastes prosódicos, como por exemplo, Frases Entoacionais Ascendentes versus Frases Entoacionais Descendentes; Frases Fonológicas Altas versus Frases Fonológicas Baixas.

A GDF opera com categorias consagradas pelas teorias fonológicas. O seu diferencial está em enfatizar a composição hierárquica dessas representações, focar sua atenção no componente prosódico das expressões lingüísticas (lócus de grande parte dos fenômenos funcionalmente relevantes para a teoria), e postular para esse nível a correlação padrão em camadas postulada para os demais níveis.

O Nível Fonológico atua a partir de input fonêmico e não fonêmico usando três conjuntos de primitivos: i) os padrões prosódicos (templates), aplicados em cada 
camada de análise; ii) um inventário de sequências segmentais, que expressam a configurações de morfemas ou de placeholders; iii) um conjunto de operadores terciários que terão seu efeito no Componente de Saída.

No Nível Fonológico, em uma organização hierárquica decrescente, de um escopo mais alto para um escopo mais baixo, estão previstas as seguintes camadas: Enunciado $\left(\mathrm{U}_{1}\right)>$ Frase Entoacional $\left(\mathrm{IP}_{1}\right)>$ Frase Fonológica $\left(\mathrm{PP}_{1}\right)$ $>$ Palavra fonológica $\left(\mathrm{PW}_{1}\right)>$ Pé $\left(\mathrm{F}_{1}\right)>$ Sílaba $\left(\mathrm{S}_{1}\right)$.

Não me deterei na especificação de cada uma das categorias do Nível Fonológico, senão em caso oportuno e de relevância para a análise aqui pretendida. Esta breve apresentação da GDF pretende oferecer uma perspectiva panorâmica do modelo e, consequentemente, demonstrar sua potencialidade descritiva como gramática tipologicamente orientada. É visível, na ampla distinção categorial sugerida pelo modelo, sua aplicabilidade no entendimento de fenômenos lingüísticos diversos. Um desses fenômenos é a gramaticalização. Trabalhos como os de Souza (2009), Hengeveld (2009, 2010), Olbertz (2010) sugerem que o modelo seja produtivo na distinção do percurso de mudança de elementos provenientes do léxico para a gramática das línguas.

\section{A Gramaticalização}

Uma discussão fundamental para a análise pretendida diz respeito à distinção da forma-fonte do processo de gramaticalização que levou ao desenvolvimento dos usos não-predicativos de [diski], haja vista que todo processo dessa natureza pressupõe alteração de valores semânticos e das propriedades categoriais. Feita essa distinção, cabe fazer uma breve incursão epistemológica que atente para a relação GDF e TG.

\subsection{A forma-fonte da gramaticalização de [disk']}

Casseb-Galvão (2001) analisou os usos predicativos e não-predicativos de dir que no português brasileiro escrito contemporâneo e atestou um processo gramaticalização que tem como forma fonte a oração matriz (ele) diz que, como uso intermediário, dizem que, e como representantes de estágios mais avançados do processo de dessemantização, os usos não-predicativos, realizados pela for- 
ma fonológica e morfossintaticamente reanalisada [disk ${ }^{i}$, funcionando como operador evidencial, conforme exemplificado de (1) a (4), acima.

Para sustentar a identificação da forma-fonte, foram acionados princípios já consagrados na literatura especializada em gramaticalização, tais como (i) e (ii).

i. Os itens fontes da gramaticalização geralmente representam experiências humanas elementares (Heine; Claudi; Hünnemeyer, 1991, p. 31), ou, nos termos de Sweetser (1990), experiências do domínio concreto, do mundo externo, sociofísico.

ii. Traços do item fonte tendem a permanecer no elemento gramaticalizado; é o que dita o princípio da persistência (Hopper, 1991).

Casseb-Galvão (2001) distinguiu a forma-fonte a partir de duas potenciais candidatas, as construções dizem que e (ele) diz que. Considerando-se o aspecto concretude, ambas as construções representarem uma experiência humana fundamental (dizer envolve um processo mental e físico), mas ele diz que tem todas as propriedades semânticas e sintáticas relativas ao predicado matriz, elemento lexical, verbo pleno, de elocução (Neves, 2000: 47-48). O mesmo não pode ser dito de dizem que, na qual não se pode identificar um agente do dito. Como o agente é um dos termos exigidos pela estrutura argumental dos verbos de elocução, dižem que pode configurar uma das escalas polissêmicas da mudança em direção à expressão gramatical da evidencialidade, provavelmente, a escala imediatamente seguinte àquela da forma fonte (ele) dir que.

Heine; Kuteva (2005, p.47) mencionam o uso evidencial reportativo de boato, rumor "They say" (eles) dizem que (She is pregnant, they say - Ela está grávida, dizem) no inglês padrão, como um fornecedor de material significativo para o desenvolvimento de usos gramaticais em situação de contato com línguas indígenas. $\mathrm{O}($ ele $)$ diz que é introdutor de discurso indireto, expressa lexicalmente evidência citativa. Trata-se de um uso no qual se explicitam o agente do dito e a fonte da informação veiculada proveniente de uma experiência evidencial indireta, conforme (5)

(5) (...) o deputado federal José Santana de Vasconcelos (PFL) prega uma grande aliança em torno do governador. Ele diz que o bom relacionamento entre o PFL, o PSDB e o PTB mineiros deve ser estendido ao plano federal. (EM-LJ) 
Obedecendo-se ao princípio da seleção restritiva, há um primeiro argumento, agente do dito, referencial, com os traços semânticos [humano], [definido], [específico] - ele (o deputado federal José Santana de Vasconcelos). Há, ainda, um segundo argumento oracional, cláusula complemento (o bom relacionamento entre 0 PFL, o PSDB e o PTB mineiros deve ser estendido ao plano federal).

Casseb-Galvão (2001) acrescenta que a constituição semântica individual dos demais componentes da construção matriz também favorece o reconhecimento de (ele) diz que como fonte do provável processo de mudança que originou os usos não-predicativos de diz que.

i. A terceira pessoa (ele), segundo Lyons (1977: 638), não está relacionada a nenhum papel participante positivo, é neutra com respeito aos participantes do ato de fala atualizado. Essa distância permanece nos traços de experiência [-direta] e [indireta] encontrados nos usos gramaticais do diz que.

ii. Que é um complementizador universal e, segundo Frajzyngier (1996: 103), tem entre suas funções duas muito especiais, uma função modal de re e de dicto, e uma função sintática de assinalar a relação funcional na combinação de cláusulas e marcar a fronteira entre elas.

Em relação aos verbos de dizerer, a distinção de dicto e de re é equivalente à distinção entre percepção direta e percepção indireta de estados, de eventos etc. Em relação aos verbos cognitivos, a distinção corresponde ao conhecimento proveniente de experiência pessoal, e ao conhecimento proveniente de boato (Frajzyngier, 1996: 91).

Esse mesmo autor identificou nas línguas tchádicas várias ocorrências de construções encaixadas com verbos de elocução gramaticalizadas em funções modais. Considerando-se a perspectiva da GFD, no Nível Interpessoal, o verbo dizer em (5) é o núcleo do Conteúdo Comunicado, que "contém a totalidade do que o falante deseja evocar em sua comunicação com o ouvinte" (Hengeveld; Mackenzie, 2008: 87). A cláusula complemento que ele seleciona funciona, no Nível Representacional, como seu argumento (op. cit.: 103). Essa função de dizer como núcleo de Conteúdo Comunicado pode ser representado por [dizer]: $\mathrm{C}_{\mathrm{i}}$

\subsection{Gramaticalização e GDF}

O modelo da GDF não foi elaborado para embasar descrições de processos de mudança lingüística. No entanto, especialmente com a publicação 
de Functional Discourse Grammar: A typologically-based theory of language structure (Hengeveld; Mackenzie, 2008), investigações cientificamente relevantes têm conciliado os postulados da GDF com os da Teoria da Gramaticalização (Souza, 2009; Hengeveld, no prelo; 2010; Olbertz, 2010).

Como resumido anteriormente, o modelo da GDF distingue níveis a partir dos quais é possível prever categorias conceituais e níveis para os quais se podem prever categorias gramaticais ou discursivamente relevantes e, portanto, tem se mostrado adequado como gramática de apoio para a descrição de processos de gramaticalização, caraterizados pelo desenvolvimento de itens ou construções conceituais ou mais ou menos conceituais (mais concretos) em itens ou construções gramaticais, mais gramaticais ou em elementos de valor discursivo (mais abstratos).

Mais especificamente, alguns fatores que contribuem para essa opção epistemológica são os seguintes:

i. O princípio de Maximal depth, a partir do qual a GDF prevê que somente níveis de representação relevantes para a construção de um enunciado são usados na sua produção e, por isso, é possível que línguas apresentem conexões diretas do Nível Interpessoal para o Nível Morfossintático, sem passar pelo Nível Representacional (Hengeveld, Mackenzie, 2008: 25). Isso é perfeitamente coerente com o princípio que reconhece bleaching, descoramento semântico ou dessemantização (Heine; Kuteva, 2004) para os elementos em processo de gramaticalização. Assim, a perda de conteúdo significativo, de nuanças conceituais em elementos mais abstratizados, pode provocar, na codificação, a transposição do Nível Representacional.

ii. Outra conseqüência dessa perspectiva é o reconhecimento de que há uma interrelação dinâmica entre os níveis de formulação e os níveis de codificação. Citando Bakker; Sierwierska (2004), Hengeved, Mackenzie (2008: 2) dizem que o "objetivo da GDF é entender como unidades lingüísticas são estruturadas em termos do mundo que elas descrevem e das intenções comunicativas com as quais elas são produz̨idas, e modela isso em uma implementação dinâmica". O dinamismo lingüístico pressupõe que alterações nos níveis pragmático e semântico, por exemplo, provocam alterações nos níveis morfossintático e fonológico. Na Teoria da Gramaticalização, tal postulação coaduna-se ao fenômeno da reanálise, caracterizada pelos rearranjos entre os domínios sistêmicos, pois é 
muito comum que, aliada à dessemantização, construções em processo de gramaticalização venham a sofrer alteração de fronteira no nível morfossintático, e, conseqüente, alteração na configuração fonológica, erosão ou redução fonética (Gonçalves et al., 2007, Heine; Kuteva, 2004).

iii. Conforme mostrado anteriormente, quanto ao escopo, a GDF prevê uma ordenação hierárquica unidirecional inter e intra níveis de organização, e a hierarquia top-down também se aplica às camadas constitutivas desses níveis. A unidirecionalidade é um recurso fundamental na análise de dados empíricos que atestem processos de gramaticalização e, para Heine; Kuteva (2005: 17), processos de gramaticalização têm essencialmente uma trajetória unidirecional. E mais, segundo Heine et al. (1991), no processo de abstratização, as categorias cognitivas são ordenadas num contínuo com a seguinte configuração: pessoa $>$ objeto $>$ processo $>$ espaço $>$ tempo $>$ qualidade. Da esquerda para a direita, significa que, nas mudanças operadas em direção à gramática ou ao discurso, as categorias cognitivas desenvolvem-se das mais próximas do indivíduo [+concretas] para as mais distantes do indivíduo [- concretas]. Em termos da GDF, significa dizer que elementos do Nível Representacional são menos gramaticalizados, têm mais carga conceitual, que elementos do Nível Interpessoal.

iv. A GFD reconhece a categorização em contínuo, ou seja, não trabalha com categorias discretas. Hengeveld; Mackenzie (2008) recorrem à noção de protótipo para distinguir elementos que modificam e elementos que especificam as variáveis nas camadas, respectivamente, modificadores (de natureza lexical) e operadores (de natureza gramatical). Mackenzie (comunicação pessoal) reconhece que historicamente modificadores podem originar operadores. E, mais que isso, na GDF, os elementos multifuncionais são analisados segundo a noção de uso, e o modelo prevê a existência de significados básicos que podem desenvolver-se em categorias voltadas para a expressão da subjetividade, como modalizadores, reportativos e evidenciais. O protótipo é o membro mais representativo de uma categoria e, a partir da noção de semelhança, serve de parâmetro para distinguir os demais membros dessa categoria. Um dos pressupostos para a distinção de processos de gramaticalização é o reconhecimento de que não há limites tão rígidos entre as categorias.

Ao analisar os usos de assim, já e ai no português brasileiro, Souza (2009: 252), em uma investigação que enfoca as categorias semânticas (propriedade, 
indivíduo, evento, episódio, conteúdo proposicional) e pragmáticas (Conteúdo comunicado, Ato discursivo e Movimento), concluiu que os usos referenciais desses elementos lingüísticos - respectivamente, advérbio de modo, advérbio de tempo e advérbio de lugar - situam-se na camada do evento, do Nível Representacional. E mais, na medida em que esses itens atuam nas camadas mais altas do Nível Representacional e nas camadas do Nível Interpessoal, assumindo funções relativas ao domínio textual (advérbio anafórico, advérbio catafórico, introdutor de episódios, advérbio relacional e conjunção coordenativa e subordinativa) e ao domínio expressivo da língua (introdutor de Conteúdo comunicado, operador aproximativo de Subato referencial e de Subato adscritivo, marcador discursivo e organizador de tópico), mais gramaticalizados eles vão se tornando, descrevendo uma trajetória unidirecional de mudança.

Nessa mesma direção, num estudo dos usos de pues, no Espanhol, um conector multifuncional que expressa causa, conclusão e uma série de propósitos pragmáticos, como por exemplo, imprimir marca de contra-expectativa, Olbertz (2010) prevê os seguintes estágios no processo de gramaticalização: i. aumento do escopo do formativo gramatical; ii. proporcional decréscimo de sua especificidade semântica e a eventual perda de seu significado, e, iii. paralela aquisição de função pragmática.

Hengeveld (no prelo), num estudo tipológico da gramaticalização das categorias de tempo e de aspecto, prevê um caminho de mudança, no interior do Nivel Representacional, que parte do Conceito Situacional para o Conteúdo Proposicional, conforme reproduzido no quadro a seguir:

\begin{tabular}{|c|c|c|c|c|c|}
\hline & $\begin{array}{l}\text { Conteúdo } \\
\text { proposicional }\end{array}$ & Episódio & Estado-de-coisas & $\begin{array}{l}\text { Conceito } \\
\text { situacional }\end{array}$ & \multirow{5}{*}{ Predicado } \\
\hline Aspecto & & & $\begin{array}{l}\text { Quantificação de } \\
\text { evento }\end{array}$ & $\begin{array}{l}\text { Aspecto fasal } \\
\text { (im)perfectividade) }\end{array}$ & \\
\hline Tempo & & $\begin{array}{l}\text { Tempo } \\
\text { absoluto }\end{array}$ & Tempo relativo & & \\
\hline $\begin{array}{l}\text { Eviden- } \\
\text { cialidade }\end{array}$ & Inferência & & $\begin{array}{l}\text { Percepção } \\
\text { evento }\end{array}$ & & \\
\hline Modo & $\begin{array}{l}\text { Modalidade } \\
\text { Subjetiva }\end{array}$ & $\begin{array}{l}\text { (ir)reali } \\
\text { dade } \\
\text { absoluta }\end{array}$ & $\begin{array}{l}\text { (ir)realidade } \\
\text { relativa }\end{array}$ & $\begin{array}{l}\text { Modalidade orienta- } \\
\text { da para o partici- } \\
\text { pante }\end{array}$ & \\
\hline
\end{tabular}

Quadro 1. Desenvolvimentos atestados na gramaticalização de tempo e de aspecto (transcrito de Hengeveld, no prelo) 
Conforme o quadro 1, um modalizador orientado para o participante, por exemplo, pode desenvolver um percurso de gramaticalização que passa pelo domínio do tempo relativo (no nível dos estados-de-coisas), pelo domínio do tempo absoluto (no nível do episódio) e pela evidencialidade inferencial (relativa ao conteúdo proposicional).

Em um trabalho que amplia as categorias de análise para Tempo, Modo e Aspecto, Hengeveld (não publicado) resume o modelo geral de trajetória de gramaticalização em quatro escalas:
(1) Nível Interpessoal: $\mathrm{M}$
$\mathrm{A} \longleftarrow \mathrm{C}$
$\longleftarrow \mathrm{T} / \mathrm{R}$
(2) Nível Representacional: $p$ e
(3) Nível Interpessoal ep
Nivel Representacional
(4) (operador)
Lexema

As escalas (1) e (2) sugerem que, no Nível Interpessoal e no Nível Representacional, a gramaticalização envolve o alargamento do escopo de operadores gramaticais. Em (3) há a indicação de que elementos do Nível Representacional, em processos de gramaticalização, podem assumir funções no Nivel Interpessoal; e (4) indica que elementos lexicais podem desenvolver-se em operadores gramaticais em qualquer nível.

Em resumo, as análises que coadunam GDF e TG prevêem a coexistência de mais de um uso para uma mesma forma, e um desenvolvimento categorial que parte do Nível Representacional, em suas sucessivas camadas, que é o lugar dos conceitos, das representações cognitivas dos eventos do mundo sociofísico, para o Nível Interpessoal, o lugar das intenções pragmáticas e das manifestações de intersubjetividade, em diferentes graus de discursivização, dependendo da camada envolvida. E, dentro do mesmo nível de organização, a trajetória de mudança partiria das camadas mais baixas para as camadas mais altas.

Os usos não predicativos de [diski] foram descritos em Casseb-Galvão (2001), Costa (2006), Corsi (2008) e Leal (2009) como integrantes de um paradigma evidencial em processo de gramaticalização no português do Brasil. Como toda categoria do domínio (inter)subjetivo da linguagem, o estatuto da evidencialidade é de difícil delimitação. No modelo da GDF, atenta-se para a complexidade conceptual dos elementos evidenciais, mas há uma tendência em relacioná-la à modalidade. 


\section{A evidencialidade na GDF}

O uso adequado de evidenciais está vinculado à categorização do modo como uma informação é adquirida. A função de evidenciais é indicar como alguém sabe, aprendeu sobre alguma coisa, como categoriza as origens do conhecimento (Aikhenvald, 2004: 365).

As grandes discussões a respeito da evidencialidade confrontam, especialmente, seu estatuto, se lexical ou gramatical (Aikhenvald, 2004; De Haan, 1998), ou, se lexical, gramatical ou pragmático (Boye; Harder, 2009).

Representando a primeira perspectiva, Aikhenvald (2004) diz que um sistema evidencial constitui um paradigma morfológico, e reconhece apenas a sua expressão de modo estrito, via afixos, clíticos ou partículas, apesar de admitir que a evidencialidade pode ser expressa por formas verbais especiais e por advérbios, como evidentemente, e, que evidenciais gramaticais podem derivar de estruturas complexas, via gramaticalização. Essa interação entre léxico e gramática pode ocorrer de diferentes maneiras, como no caso de verbos dicendi (dižer, falar) ou de percepção (ver, parecer), que adquirem significados evidenciais não-básicos.

Em tal concepção, há uma oposição rigorosa entre itens lexicais e itens gramaticais e, para Aikhenvald (2008), o verdadeiro evidencial tem a origem da informação como seu significado nuclear, ou seja, a sua interpretação não marcada, padrão. Em línguas com marcação obrigatória da evidencialidade, a falta dessa marca morfológica provocaria agramaticalidade à sentença ou atribuiria artificialidade ao discurso.

Essa delimitação da evidencialidade como categoria gramatical afasta-se da idéia de categorialidade em contínuo, pilar da Teoria da Gramaticalização, apesar de Aikhenvald (2004) fazer distinção entre diferentes sistemas evidenciais, e também entre estratégias evidenciais (modalizadores ou outras categorias que assumem um valor evidencial não-primário, não-básico) e evidenciais propriamente ditos.

Cada evidencial tem uma história própria e uma trajetória de desenvolvimento. Um evidencial pode vir de um verbo dicendi ou de um verbo de percepção. Ou pode desenvolver-se de uma outra classe aberta ou fechada via gramaticalização e reanálise. Um sistema evidencial mais 
restrito pode se desenvolver de estratégias evidenciais (Aikhenvald, 2004: 21).

Ao questionar-se a respeito do como o usuário da língua escolhe o evidencial adequado em uma situação de confronto entre mais de um caminho possível para se obter uma determinada informação, Aikhevald (2004) reconhece regras de preferência, e diz que evidenciais se tornam convencionalizados em diferentes gêneros e estilos de discurso, e que uma escolha evidencial não esperada produz efeitos retóricos adicionais.

Uma abordagem ampla da evidencialidade vem de Boye; Harder (2009). Para eles, a definição do estatuto da evidencialidade extrapola a distinção lexical versus gramatical, valor semântico versus pragmático e informação primária versus informação secundária. Não que essas distinções sejam irrelevantes. A idéia é que a evidencialidade deveria ser entendida como um domínio de substância conceptual-funcional, uma noção pertencente à significação, e não como algo definível a partir de distinções de qualquer natureza. Domínios de substância são estruturados de diferentes maneiras, logo é necessário tomar critérios conceptuais e estruturais separadamente. E, partindo-se da noção de que significados ou conteúdos motivam a morfossintaxe, e, em alguns casos, a fonologia, um fator fundamental para se entender o fenômeno da evidencialidade é pensá-lo sob o viés da gramaticalização e dos fenômenos a esta associados (vinculação, redução fonológica, obrigatoriedade de uso, aumento de freqüência etc).

Essa perspectiva aberta da evidencialidade vai ao encontro da GDF. Neste modelo, ela é concebida como uma categoria complexa, relativa à fonte do conhecimento enunciado, relevante em diferentes níveis e camadas da constituição linguística geral, pois categoriza tanto noções Interpessoais quanto noções Representacionais (Hengeveld; Mackenzie, 2008, Hattnher; Hengeveld, em preparação). Isso significa que o modelo contempla o fenômeno da evidencialidade a partir de seu potencial conceptual e funcional, ou seja, a partir das possibilidades significativas que porventura os elementos evidenciais possam expressar na atualização linguística, mas também atenta para a função dos evidenciais em relação a um núcleo morfossintático, às estratégias pragmáticas, aos efeitos de sentido promovido entre os interlocutores e aos valores concepuais que eles codificam. Em outras palavras, na GDF, a evidencialidade não se distingue apenas por seu estatuto, se lexical, gramatical ou pragmático, mas 
por sua funcionalidade na atualização linguística, considerando-se o dinamismo e a interação entre os níveis de organização linguística.

Hengeveld; Mackenzie (2008) distinguem o domínio conceptual-funcional da evidencialidade em dois sistemas, o sistema reportativo e o sistema evidencial modal. O nível de atuação, a função linguística encarecida, e o sistema evidencial que realizam são os parâmetros para classificar os tipos evidenciais, a saber:

Do Nível Interpessoal: Evidencialidade reportativa (manifestação pragmática da evidencialidade).

I. Sistema reportativo: indicador de que o falante está transmitindo, relatando uma informação que ouviu de um terceiro, e não propriamente informando. Evidenciais reportativos incidem sobre o Conteúdo Comunicado. Este diz respeito à totalidade do que o falante espera evocar em sua comunicação com o ouvinte, corresponde às escolhas que o falante faz na medida em que evoca o quadro do mundo externo sobre o qual ele quer falar, é a unidade dentro da qual o Nível Representacional é mapeado (Hengeveld; Mackenzie, 2008: 87).

II. Do Nível Representacional - Modalidade evidencial (relacionada à origem do conhecimento enunciado e à atitude do falante) - Manifestação semântica da evidencialidade.

1. Relacionada ao modo como o falante chegou a um certo conhecimento contido no Conteúdo Proposional. Conteúdos Proposicionais são construtos mentais que não existem no espaço e no tempo, mas existem na mente dos envolvidos no ato comumicativo. Conteúdos Proposicionais podem ser factuais, quando são partes de conhecimento ou crença razoável a respeito do mundo atual, ou não factuais, quando eles são desejos ou esperanças a respeito de um mundo imaginário. Os sistemas evidenciais representados nesse nível são:
a) sistema evidencial inferencial: Pode ser de natureza sensorial direta, a partir de evidência visual, ou de natureza indireta (não visual), derivada de um conhecimento existente.
b) sistema evidencial de genericidade: a origem do conheci- mento contido no Conteúdo Proposicional é baseado em um conhecimento geral acumulado na comunidade.

2. Relacionada ao modo de percepção dos eventos. 
c) Sistema evidencial perceptual: o conhecimento é obtido a partir de percepção direta do Estado-de-Coisas (ou de sua ausência) descrito na cláusula. Um Estado-de-coisas é uma entidade que pode ser localizada no tempo relativo e pode ser avaliada em termos de sua realidade.

O quadro a seguir resume essa perspectiva.

\begin{tabular}{|l|l|l|l|}
\hline Nível & Função & Sistema evidencial & Estatuto categorial \\
\hline Interpessoal & Pragmática & Reportativo & Categoria-C \\
\hline Representacional & Semântica & $\begin{array}{l}\text { Inferencial (visual, não- } \\
\text {-visual), } \\
\text { Genericidade }\end{array}$ & Categoria-p \\
\hline & Percepção de evento & Categoria-e \\
\hline
\end{tabular}

Quadro 2. Evidencialidade na GDF

Hattnher; Hengeveld (no prelo) esquematizam a expressão interlinguística da evidencialidade em diferentes camadas:

$$
\begin{gathered}
\left(\mathrm{A}_{1}:\left[\left(\mathrm{F}_{1}\right)\left(\boldsymbol{\Pi}^{\mathrm{C}} \mathrm{C}_{1}:\left[-------\mathrm{C}_{1}\right)\right)\right]\left(\mathrm{A}_{1}\right)\right) \\
\left(\boldsymbol{\pi}^{\mathrm{p}} \mathrm{p}_{1}:\left(\mathrm{ep}_{1}:\left[\left(\boldsymbol{\pi}^{\mathrm{e}} \mathrm{e}_{1}\right)\right]\left(\mathrm{ep}_{1}\right)\right)\left(\mathrm{p}_{1}\right)\right)
\end{gathered}
$$

Modalidade reportativa $\left(\Pi^{\circ}\right)$ : operador de Conteúdo Comunicado

Modalidade inferencial $\left(\pi^{\mathrm{p}}\right)$ : operador de Conteúdo proposicional

Percepção de evento $\left(\pi^{\mathrm{e}}\right)$ : operador do nível dos estados-de-coisas.

As reflexões anteriores, relativas à GDF, à Gramaticalização e à Evidencialidade servirão de base para a análise dos dados.

\section{Análise dos dados}

Uma análise que relaciona TG e GDF deve conciliar um estudo da forma-fonte e dos usos-alvo, numa visão unidirecional do processo de desenvolvimento desses novos usos, prevendo fenômenos como dessemantização, 
aumento de escopo e pragmatização, visíveis a partir da organização gramatical em níveis e camadas postulados na GDF.

Portanto, a partir do que se tem descrito (Hengeveld, 2010; Olbertz, 2010; Souza, 2009) e considerada a forma fonte do processo (ele diz que) que integra o núcleo de Conteúdo Comunicado, no Nível Interpessoal, espera-se uma trajetória de gramaticalização em que os usos dele derivados integrem níveis mais altos dessa camada, ou seja, numa escala ascendente, a camada dos Participantes $\left(\mathrm{P}_{1}\right)\left(\mathrm{P}_{2}\right)$, da Ilocução $\left(\mathrm{F}_{1}\right)$, do Ato Discursivo $\left(\mathrm{A}_{1}\right)$ ou do Move $\left(\mathrm{M}_{1}\right)$.

\subsection{Os usos de [disk ${ }^{\mathrm{i}}$ no português do Brasil}

Além da forma-fonte do processo de gramaticalização de [diski], outros integrantes da cadeia polissêmica que originou os usos mais abstratos são dizem que e diž-se que, construções lexicais indicadoras de boato, no português brasileiro e no português europeu, respectivamente.

O significado central expresso pelos usos de [diski] é a impessoalidade. Mas, considerando-se a evidencialidade como uma macro-categoria, um domínio de substancia funcional-conceptual, como sugerem Boye; Harder (2009), é possível dizer que essa impessoalidade é resultado do modo como o conhecimento enunciado foi originado, ou seja, por evidência indireta: a fonte do conhecimento enunciado é de ouvir dizer, fruto de conhecimento geral ou inferida a partir de outro conhecimento. Contextualmente, esses usos codificam diferentes estratégias (inter) subjetivas. É o que se pode perceber nos usos a seguir, analisados segundo os papéis semânticos e as propriedades categoriais postuladas na GDF. A ordem de análise considera o nível e a camada que o uso integra, em uma trajetória unidirecional de [+conceitual] para [+abstrato], [+ discursivo].

\subsection{1 $\left[\text { disk }^{\mathrm{i}}\right]_{1}$ "Verdade geral"}

\section{- Diz que mulher tem alma de gato.}

Nesse uso, o [diski] exerce o papel semântico de introdutor de verdade geral, introduz um conhecimento compartilhado por uma comunidade de fala, originado em inferência proveniente desse conhecimento partilhado, faz distinções a respeito de uma evidência genérica, especifica um Conteúdo Proposicional, conforme representado a seguir:

$$
\left(\left[\operatorname{disk}^{i}\right] \mathrm{p}_{\mathrm{i}}:[\ldots]\left(\mathrm{p}_{\mathrm{i}}\right)\right)
$$


Segundo os postulados da GDF, as seguintes propriedades podem ser atribuídas ao [diski $]_{1}$ "verdade geral":

a) Não pode estar no escopo de tempo nem de negação.

(6) * Ontem, dir que cabelo raspado, quando cresce vem até mais cacheado.

Conforme se pode observar em (6), a presença do modificador temporal absoluto, ontem, não traz qualquer acréscimo significativo ou funcional, e a sentença torna-se agramatical.

(7) * Não dir que cabelo raspado, quando cresce, vem até mais cacheado...

Em (7), a única leitura possível ao se acrescentar a negação é de leitura enfática, a polaridade da sentença não foi alterada. Em uma leitura gramaticalmente aceita da sentença, não pode ser considerado um modificador de Conteúdo Comunicado, um intensificador do conteúdo do Ato Discursivo (Hengeveld; Mackenzie, 2008: 102).

b) O verbo da proposição é sempre no presente.

O tempo no presente atualiza o Estado-de-Coisas descrito, atribuindo-lhe validade atemporal.

\subsection{2 $\left[\text { disk }^{\mathrm{i}}\right]_{2}$ "token de narrativa"}

(8) Diz que um leão enorme ia andando chateado, não muito rei dos animais porque tinha acabado de brigar com a mulher e esta lhe dissera poucas e boas. (LR) ${ }^{10}$

$\mathrm{O}\left[\text { disk }^{\mathrm{i}}\right]_{2}$ “token de narrativa” constrói o mundo no qual o enunciado terá validade comunicativa: o mundo narrativo ficcional, um universo proposicional alternativo. Trata-se, portanto, de um elemento do Nível Representa-

9 Token de narrativa é a denominação usada por Aikhenvald (2004) para identificar, interlinguisticamente, um tipo evidencial caracterizador de gênero narrativo e que tem propriedades muito semelhantes àquelas verificadas para este uso de [diski].

10 Literatura Romanesca. 
cional, um introdutor de episódio. Segundo Hengeveld; Mackenzie (2008: 157) Episódio (ep) é constituído por um ou mais Estados-de-Coisas (e), tematicamente coerentes, no sentido de que eles mostram unidade ou continuidade no Tempo (t), no Espaço (Localização - l), e em relação aos indivíduos (x). A representação a seguir indica esse uso como introdutor de episódio.

$\left(\left[\operatorname{disk}^{\mathrm{i}}\right] \mathrm{ep}_{\mathrm{i}}:\left[\left(\mathrm{e}_{\mathrm{i}}\right) \ldots\left(\mathrm{ep}_{\mathrm{i}+\mathrm{N}}\right)\right]\left(\mathrm{ep}_{\mathrm{i}}\right)\right)$

Segundo Casseb-Galvão (2010: 134), [disk'i ${ }_{2}$ “token de narrativa”

instaura o tom mágico, a poesia, a cor da terra, inerentes ao mundo discursivo que se quer construir. Esses fatores, aliados ao conteúdo informacional produzem um tipo narrativo especial, a narrativa mítica folclórica, uma transformação de gêneros de predominância narrativa tradicional como os contos, por exemplo.

As propriedades que distinguem o $\left[\mathrm{disk}^{\mathrm{i}}\right]_{2}$ "token de narrativa" são as seguintes:

a) O conjunto de Estados-de-Coisas tem configuração temporal absoluta, está localizado no passado. Hengeveld; Mackenzie (2008: 163) dizem que essa é uma propriedade dos Episódios. A localização temporal relativa é propriedade de Estados-de-Coisas.

b) Pode estar no escopo de um modificador temporal relativo de episódio, como há muitos e muitos anos, conforme (9):

(9) Há muitos e muitos anos, diz que um rei tinha uma filha por casar...

c) Não aparece em contexto holofrástico, logo, não recupera um conteúdo semântico pré-existente, mas integra o conjunto significativo que constitui o episódio.

Holófrases são formas não clausais que oferecem uma contribuição completa ao discurso. Como a resposta um biscoito à pergunta O que você está comendo? ou ainda frases como Congratulações! Oh, João! (Hengeveld; Mackenzie, 2008: 3-4). É no mínimo “estranho" que, ao final da narrativa, o interlocutor tente confirmar a veracidade do Conteúdo Comunicado e o locutor use o $\left[\right.$ disk $^{i}{ }_{2}$ como resposta. Diferentemente do que ocorre com o uso a seguir, evidencial de boato. 


\subsection{3 $\left[\text { disk }^{i}\right]_{3}$ de boato}

(10) Entonce, tavam lá arranchado uns comboieros que tinham arrumado o eito, assim pua banda, ia porção de surrão de mio, que fazia assim mod'um escuro. Aí diz que virum a muié do Venanço non sei [no escuro com outro homem] (DGP)

$\mathrm{O}\left[\mathrm{disk}^{\mathrm{i}}\right]_{3}$ de boato indica que o conhecimento é proveniente de uma terceira pessoa. $\mathrm{O}$ falante está muito mais transmitindo, relatando o que ouviu do que informando algo. É um Evidencial Reportativo: incide sobre a totalidade do que o falante deseja evocar no interlocutor a respeito do Conteúdo Comunicado e, portanto, é um elemento do Nível Interpessoal.

As propriedades de $\left[\mathrm{disk}^{\mathrm{i}}{ }_{3}\right.$ de boato são as seguintes:

a) Combina-se com ilocução interrogativa (integrante do Nível Interpessoal), como se observa em (10):

(10) - Menino, diz que você qué pedi moça?? Menino, deixe disso, você não conhece ainda o trivial do casamento... Tome meu conselho! (DGP)

b) Introduz respostas do tipo $\operatorname{sim}$ e não, o que significa que ele não integra o Nível Semântico, Representacional, mas atua no domínio das relações interlocutivas, conforme se observa em (11):

(11) A - E a mulher?

B - Levaram lá pra dentro.

A - Diz que lá dentro escutam a gente sim. (...)

$\mathrm{B}$ - Diz que às vezes eles ligam a choradeira das mães para os presos ouvirem.

\section{A - Dizque é. (LR)}

O uso sublinhado pode ser representado por $\left(\operatorname{disk}^{i} C_{I}:\left(p_{i}: \text { é }\left(p_{j}\right)\right)^{11}\right.$, o que significa que o $\left[\mathrm{disk}^{i}\right]_{3}$ é núcleo de um Conteúdo comunicado que, no Nível Representacional, equivale a um Conteúdo proposicional recuperado do contexto anterior a partir do operador de polaridade expresso pelo verbo ser.

c) Introduz um Conteúdo Comunicado mapeado a partir de um quantificador de propriedade, na ocorrência a seguir o quantificador muito, logo, ocorre em contexto holofrástico, o que pode ser representado por $\operatorname{diq} q u e C=\left(f_{i}\right.$ : muito $\left.\left(f_{i}\right)\right)$

11 O símbolo de igualdade indica uma correspondência entre o NI e o NR. 
(12) A - Ti Jaquim rifiria qui a Senhora era Cuma cavalo cacete, qui tem sinau incoberto.

B - Era muito rica?

A - Diz qui muito.

B -Possuía muito ouro?

A - Diz qui munto.

B - Inhor, sim. Cuieres, copo, bacia, jarro... Mais tava tudo cage sempre trancado, só butava pra fora dia de festa... (DGP)

Heine; Kuteva (2005: 74) reconhecem o uso de [diski] reportativo, de boato como uma expressão evidencial do português brasileiro usada, em situação de contato, por falantes Tariana.

\subsection{4 $\left[\text { disk }^{\mathrm{i}}\right]_{4}$ admirativo}

(...) estas férias diz-que não é pra en fazer nada. Qual! descobri um livro de vulgarização do Wella, The Science of Life, que é uma coisa magnifica. (MA)

$\mathrm{O}\left[\text { disk }_{4}\right]_{4}$ admirativo indica a admiração do falante a respeito do Conteúdo Proposicional evocado pelo Conteúdo Comunicado. É um integrante da categoria ilocucionária, um elemento do Nível Interpessoal.

Para Aikhenvald (2004), o admirativo é uma categoria evidencial e para Olbertz (2009), é uma categoria semântica modal, integrante do Nível Representacional. Mas, Hengeveld; Mackenzie (2008), considerando a estratégia pragmática que admirativos realizam, os incluem entre as estratégias ilocucionárias básicas. Aikhenvald (2004: 158) também faz distinção entre essas duas categorias, mas reconhece uma interrelação entre admirativos e evidenciais, e diz que, em sistemas evidenciais restritos, de duas escolhas, evidenciais que expressam informação proveniente de um terceiro podem ampliar-se para cobrir nuanças relativas a informações novas, não usuais e surpresas.

Os dados parecem confirmar essa interrelação e sugerem que a função admirativa seja um dos elos da cadeia de gramaticalização gerada pelos usos de [disk ${ }^{i}$, haja vista que no [disk ${ }_{4}{ }_{4}$ admirativo persiste a nuança de evidência indireta, informação sem fonte definida. 
As propriedades observadas no [diski $]_{4}$ admirativo são as seguintes

a) Não introduz um Ato Discursivo declarativo propriamente dito. A leitura admirativa é especialmente perceptível no contorno entoacional, pois o [diski] é o contexto de maior proeminência no complexo entoacional a que pertence.

b) Pode ocorrer em um Ato Discursivo interrogativo, sem perder o valor admirativo.

(13) (...) estas férias diz-que não é pra en fazer nada?

a) $\left(\left[\operatorname{disk}^{\mathrm{i}}\right] \mathrm{F}_{\mathrm{I}}:\left[\left(\mathrm{P}_{\mathrm{I}}\right)\left(\mathrm{P}_{\mathrm{J}}\right)\left(\mathrm{C}_{\mathrm{I}}\right)\right]\left(\mathrm{F}_{\mathrm{I}}\right)\right)$

O quadro a seguir resume, segundo a GDF, os aspectos categoriais e funcionais verificados para os usos de [disk $\mathbf{d}^{\mathrm{i}}$.

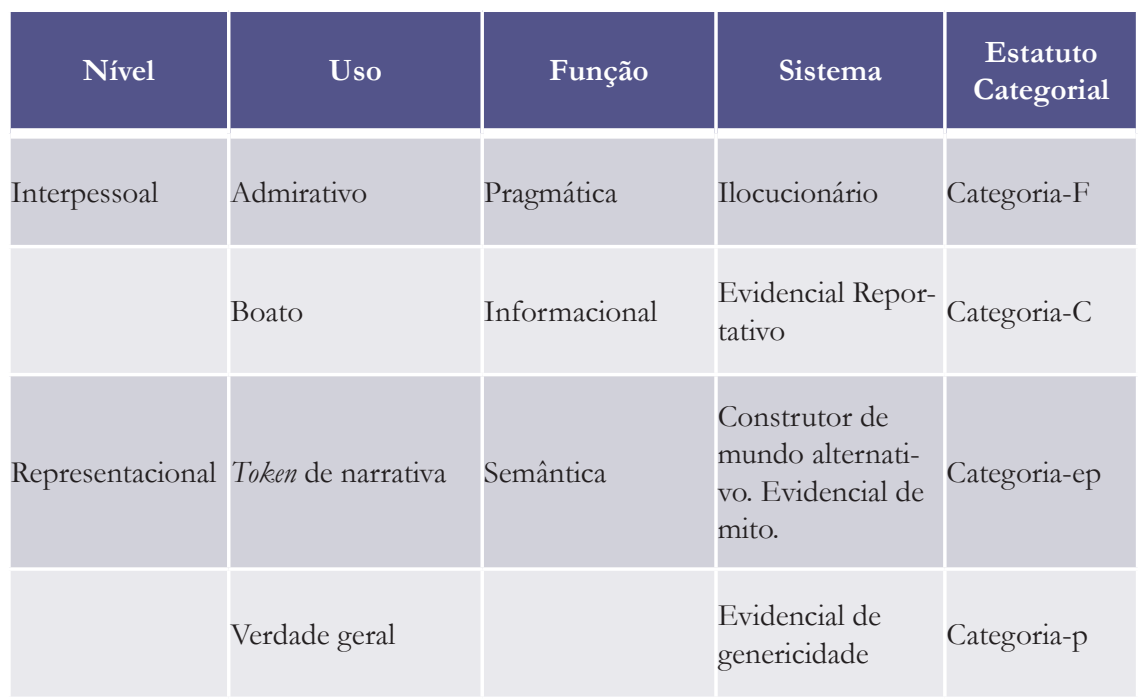

Quadro 3. Aspectos categoriais e funcionais dos usos de [disk $\left.{ }^{\mathrm{i}}\right]$, segundo o modelo da GDF 
A interpretação do quadro 3, relacionando-se TG e GDF, sugere que o cline de gramaticalização descrito pelos usos de [diski] seria bifurcado:

\begin{tabular}{cc}
\hline Nivel Representacional & Nível Interpessoal \\
verdade geral $<$ token de narrativa & $<$ (Ele) diz que $>$ reportativo $>$ admirativo \\
\hline
\end{tabular}

Quadro 4. Cline de gramaticalização de [disk'] a partir da organização gramatical proposta pela GDF

Assim, considerando-se (Ele) diz que como forma fonte do processo, haveria tanto um desenvolvimento em direção às camadas mais altas do Nível Interpessoal (usos reportativo e admirativo), como um desenvolvimento em direção ao Nível Representacional (token de narrativa). Tal resultado contradiz o princípio da unidirecionalidade ${ }^{12}$.

\section{Conclusões}

A análise anterior parece fugir aos postulados da GDF, que descreve o verbo dizer como Introdutor de Conteúdo Comunicado (Hengeveld; Mackenzie, 2008: 276), e, sendo assim, deveria derivar elementos de camadas mais altas dentro do Nível Interpessoal. No entanto, usos como o [diski] token de narrativa e o [diski] de genericidade ocupam camadas mais baixas na organização lingüística. Essa contradição também questiona o princípio da unidirecionalidade, a partir do qual se espera que o desenvolvimento de elementos em gramaticalização ocorra dos usos [+ concretos], [+ conceituais] para os [+abstratos], e, portanto, do nível semântico para o nível pragmático.

Tais constatações sugerem adaptações no modelo da GDF.

Um primeiro direcionamento é relativo aos níveis de organização lingüística. Seria adequada a propositura de um Nível relativo às funções exclusivamente textuais, o Nível Retórico, para descrever usos como o [diski] ${ }_{2}$ token de narrativa.

Essa não é uma ideia inédita nos estudos da GDF. Hengeveld; Mackenzie (2008) optaram por incluir as variáveis relativas à composição estrutural e ar-

12 Na TG, é previsto para o continuo descrito pelos elementos em gramaticalização um traçado unidirecional em que a forma-fonte [+ lexical] ocupa o ponto mais extremo à esquerda. 
gumentativa do texto no Nível Interpessoal, mas Hengeveld (1997), ao estudar o fenômeno da coesão, postula que as variáveis relativas ao discurso como um todo, ao tipo de discurso e aos moves (movimentos) que o constituem sejam alocados no Nível Retórico. As unidades subjacentes ao Nível Retórico seriam o Parágrafo, o Frame Discursivo e o Texto.

Um segundo direcionamento diz respeito à distinção dos evidenciais dentro do quadro da GDF. Hengeveld; Mackenzie (2008) descrevem a genericidade no Nível Representacional, mas, se considerarmos que na expressão da verdade geral, de um conhecimento comum, não há uma voz individualizada, pode-se perfeitamente compreender que a natureza desse tipo evidencial também é reportativa: o falante está apenas transmitindo um conhecimento prévio, está apenas relembrando ao ouvinte uma verdade conhecida de todos. E, portanto, os elementos que exercem essa função atuariam no Nível Interpessoal e não no Nível Representacional.

O desenvolvimento das sugestões anteriores requer a continuidade das investigações, especialmente, a partir de uma abordagem tipológica.

O quadro a seguir esquematiza a reorganização aqui proposta.

\begin{tabular}{|c|c|c|c|c|}
\hline Nível & Uso & Função & Sistema & $\begin{array}{l}\text { Estatuto } \\
\text { Categorial }\end{array}$ \\
\hline Retórico & $\begin{array}{l}\text { Token de nar- } \\
\text { rativa }\end{array}$ & Retórica & $\begin{array}{l}\text { Construtor de frame } \\
\text { de mundo narrado, de } \\
\text { narrativa ficcional. }\end{array}$ & Categoria textual \\
\hline \multirow[t]{3}{*}{ Interpessoal } & Verdade geral & Informacional & $\begin{array}{l}\text { Evidencial de generi- } \\
\text { cidade }\end{array}$ & $\begin{array}{l}\text { Categoria-A } \\
\text { (Mapeada em um } \\
\text { único ato discursivo) }\end{array}$ \\
\hline & Admirativo & Pragmática & Ilocucionário & Categoria-F \\
\hline & Boato & Informacional & $\begin{array}{l}\text { Evidencial Repor- } \\
\text { tativo }\end{array}$ & Categoria-C \\
\hline
\end{tabular}

Quadro 5. Sistema esboçado pelos usos de [disk $\left.{ }^{i}\right]$ no português do Brasil 


\section{Referências bibliográficas}

AIKHENVALD, A.(2004). Evidentiality. Oxford: Oxford University Press.

BOYE, K.; HARDER, P. (2009). Evidentiality: Linguistic categories and grammaticalization. Functions of Language. 16/1. 9-43. Amsterdam/Philadelphia: John Benjamins.

CASSEB-GALVÃO, V. C. (2001). Evidencialidade e gramaticalização no português do Brasil: os usos da expressão diz que. Tese de Doutorado em Lingüística e Lingua Portuguesa. Faculdade de Ciências e Letras, Universidade Estadual Paulista, Campus de Araraquara. Araraquara.

. (2010). Uma propriedade distintiva na gramaticalização de um operador evidencial reportativo: token de narrativa. In: LIMA-HERNANDES, Maria Célia (Org.). Gramaticalização em perspectiva: cognição, textualidade e ensino. São Paulo: Paulistana, p. 121-138.

COSTA, A. N. (2006). Os usos evidenciais não-predicativos de diz que: um estudo em tempo real de curta duração. Relatório final PIBIC. Goiânia / UFG (não publicado).

CORSI, S. S. (2007). Os usos evidenciais predicativos e não-predicativos do diz que no português histórico do Brasil (Do Séc. XIII ao séc. XX). Relatório final PIBIC. Goiânia / UFG. (não publicado).

DE HAAN, F. (1998). The Category of Evidentiality. (não publicado)

FRAJZYNGIER, Z. (1996). Grammaticalization of the complex sentence. A case study in Chadic. Amsterdam/Philadelphia: John Benjamins.

GONÇALVES, S. C. L et al. (2007). Introdução à gramaticalização. São Paulo: Parábola. HATTNHER; M.; HENGEVELD, K. Evidentiality in Functional Discourse Grammar. (não publicado).

HEINE, B. CLAUDI, U.; HÜNNEMEYER, F. 1991. Grammaticalization: A conceptual framework. Chicago: The University of Chicago Press.

HEINE, B; KUTEVA, T. (2004). World lexicon of grammaticalization. Cambridge: Cambridge University Press.

University Press.

(2005). Language contact and grammatical change. Cambridge: Cambridge

HENGEVELD, K. (1997). Cohesion in Functional Grammar. In: BUTLER, C. S. et al. Discourse and pragmatics in Functional Grammar (Functional Grammar Series 18), 1-16. Berlin: Mouton de Gruyter.

. (2004). Epilogue. In. MACKENZIE, J. L; GÓMEZ-GONZÁLEZ, M. A. A

New architecture for Functional Grammar. Berlin: Mouton de Gruyter, p. 365-78.

. (2011). The grammaticalization of tense and aspect. To appear in Bernd Heine \& Heiko Narrog eds, The Oxford Handbook of Grammaticalization. Oxford: Oxford University Press. 
. The grammaticalization of Tense, Mood and Aspect in FDG. International Conference on Functional Discourse Grammar (2010). Lisbon. (não publicado)

HENGEVELD, K.; MACKENZIE, J. L. (2008). Functional Discouse Grammar: a typologically-based theory of language structure. Oxford: Oxford University Press.

HOPPER, P. (1991). On some principles of grammaticalization. In: TRAUGOTT, E. C.; HEINE, B. (orgs.). Approaches to Grammaticalization II. Amsterdam: John Benjamins, 17-36.

LEAL, C. B. (2009). Os usos evidenciais gramaticalizados de dir que em romances regionalistas brasileiros. Relatório final PIBIC. Goiânia / UFG. (não publicado).

LYONS, J. 1977. Semantics. Cambridge: Cambridge University Press.

MACKENZIE, J. L.; GÓMEZ-GONZÁLEZ, M. Á. (eds.). (2004). A New Architecture for Functional Grammar (Functional Grammar Series 24). Berlin: Mouton de Gruyter. . (eds.) (2005). Studies in Functional Discourse Grammar (Linguistic Insights 26). Berne, Berlin, Brussels, Frankfurt a. M., New York, Oxford, and Vienna: Peter Lang. NEVES, M. H. M. (2000). Gramática de usos do português. São Paulo: Editora da UNESP, 2000.

OLBERTZ, H. (2009). Mirativity and exclamatives in Fuctional Discurse Grammar: evidence from Spanish. In: Web papers in Functional Discourse Grammar, no 82, p. 66-82. . (2010). The grammaticalization of the Spanish connector pues - a proposal for an FDG account. International Conference on Functional Discourse Grammar . Lisbon, (não publicado)

ROSA, I. F. (2004). Os usos do diz que evidencial em inquéritos do tipo entrevista com documentador (NURC/DID). Relatório final PIBIC, 2004. Curso de Letras, Campus de Catalão/ UFG. (não-publicado).

SWEETSER, E. (1990). From etymology to pragmatics. Cambridge: Cambridge University Press.

SOUZA, E. R. F. (2009). Gramaticalização dos itens lingüisticos assim, já e ai no Português Brasileiro: um estudo sob a perspectiva da Gramática Discursivo-Funcional. Tese de Doutorado em Linguística. Instituto de Estudos da Linguagem. Campinas: Universidade Estadual de Campinas. .

Recebido em: 22/01/2011

Aprovado em: 25/05/2011 